\title{
BMJ Open Education level and survival after oesophageal cancer surgery: a prospective population-based cohort study
}

\author{
Nele Brusselaers, ${ }^{1}$ Rickard Ljung, ${ }^{1}$ Fredrik Mattsson, ${ }^{1}$ Asif Johar, ${ }^{1}$ Anna Wikman, ${ }^{1}$ \\ Pernilla Lagergren, ${ }^{1}$ Jesper Lagergren ${ }^{1,2}$
}

To cite: Brusselaers N, Ljung R, Mattsson F, et al. Education level and survival after oesophageal cancer surgery: a prospective population-based cohort study. BMJ Open 2013;3:e003754. doi:10.1136/bmjopen-2013003754

- Prepublication history and additional material for this paper is available online. To view these files please visit the journal online (http://dx.doi.org/10.1136/ bmjopen-2013-003754).

Received 8 August 2013 Revised 22 October 2013 Accepted 7 November 2013

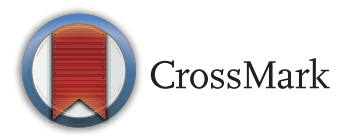

${ }^{1}$ Unit of Upper Gastrointestinal Research, Department of Molecular Medicine and Surgery, Karolinska Institutet, Stockholm, Sweden 2Division of Cancer Studies, King's College London, London, UK

Correspondence to Dr Nele Brusselaers; nele.brusselaers@ki.se

\section{ABSTRACT}

Objectives: This study aimed to investigate whether a higher education level is associated with an improved long-term survival after oesophagectomy for cancer.

Design: A prospective, population-based cohort study. Setting: Sweden-nationwide.

Participants: $90 \%$ of all patients with oesophageal and cardia cancer who underwent a resection in Sweden in 2001-2005 were enrolled in this study ( $\mathrm{N}=600$; $80.3 \%$ male) and followed up until death or the end of the study period (2012). The study exposure was level of education, defined as compulsory ( $\leq 9$ years), moderate (10-12 years) or high ( $\geq 13$ years).

Outcome measures: The main outcome measure was overall 5-year survival after oesophagectomy. Cox regression was used to estimate the associations between education level and mortality, expressed as HRs with $95 \%$ Cls, with adjustment for sex, age, tumour stage, histological type, complications, comorbidities and annual surgeon volume. The patient group with highest education was used as the reference category.

Results: Among the 600 included patients, 281 (46.8\%) had compulsory education, 238 (39.7\%) had moderate education and $81(13.5 \%)$ had high education. The overall 5 -year survival rate was $23.1 \%, 24.4 \%$ and $32.1 \%$ among patients with compulsory, moderate and high education, respectively. After adjustment for confounders, a slightly higher, yet not statistically significantly increased point $\mathrm{HR}$ was found among the compulsory educated patients (HR $1.08,95 \% \mathrm{Cl} 0.80$ to 1.47). In patients with tumour stage IV, increased adjusted HRs were found for compulsory (HR 2.88, 95\% Cl 1.07 to 7.73 ) and moderately (HR 2.83, 95\% $\mathrm{Cl} 1.15$ to 6.95) educated patients. No statistically significant associations were found for the other tumour stages. Conclusions: This study provides limited evidence of an association between lower education and worse longterm survival after oesophagectomy for cancer.

\section{INTRODUCTION}

Oesophageal cancer is characterised by an increasing incidence in many Western populations, and the 5-year overall survival is less

\section{Strengths and limitations of this study}

Nationwide population-based design with high participation rate and completeness of the follow-up, consequently reducing the risk for selection bias.

- Robust definitions of exposure and outcome reducing the risk of misclassification.

- Limited statistical power to detect weak or moderate differences, particularly in the stratified analyses.

than $15 \%$ in Europe. ${ }^{12}$ A low socioeconomic position is a risk factor for two main histological types of oesophageal cancer, that is, adenocarcinoma and squamous cell carcinoma. The role of the socioeconomic position in the development of oesophageal carcinoma can only partly be explained by the main risk factors, that is, gastro-oesophageal reflux and obesity for adenocarcinoma and tobacco smoking and heavy alcohol intake for squamous cell carcinoma. ${ }^{13}{ }^{4} \mathrm{~A}$ recent study indicated that the mortality rates for oesophageal cancer were lower in patients with a higher education level. ${ }^{5}$ Education has been studied more extensively in relation to survival of other types of cancer, ${ }^{6-10}$ showing a beneficial effect of higher education on survival that might be explained by the differences in comorbidity burden, lifestyle factors, health awareness, adherence to treatment and healthcare seeking behaviour, factors which are also likely to influence the timing of referral and tumour stage at diagnosis. ${ }^{6-10}$ The impact of education on survival after oesophageal cancer diagnosis has been examined in cohort studies, ${ }^{3} 11{ }^{12}$ but no clear associations were found. Two studies have evaluated the influence of the socioeconomic position on survival after oesophagectomy for cancer, ${ }^{13}{ }^{14}$ where one showed no long-term survival advantage of higher 
socioeconomic position, ${ }^{13}$ while the other study showed a better short-term survival. ${ }^{14}$ Thus, the prognostic role of socioeconomic position in patients with oesophageal cancer remains uncertain. A better insight into this association might improve preoperative decision-making and information, and postoperative management, survival and health-related quality of life. The objective of this study was to clarify the influence of education level on the overall and disease-specific survival after curatively intended oesophageal cancer surgery using a nationwide population-based design with a long-term follow-up.

\section{PATIENTS AND METHODS}

\section{Study design and data sources}

This was a nationwide Swedish prospective, populationbased cohort study. All surgically treated patients with oesophageal or cardia cancer in Sweden during the period April 2001 and December 2005 were eligible for the study. The follow-up for survival ended in August 2012.

\section{Data sources}

In September 2012, the following Swedish registers were linked:

The Swedish Esophageal and Cardia Cancer database (SECC): SECC was used to identify the study cohort and assess the data on clinical factors. This database is our all-encompassing, nationwide Swedish research database, including $90 \%$ of all patients with oesophageal and cardia cancer treated with surgery in Sweden during the inclusion period. The organisation of the nationwide network of clinicians and the design of this study have been described in detail elsewhere. ${ }^{15} 16$ In brief, SECC contains prospectively collected and detailed information about tumour pathology and localisation, tumour stage, surgical procedures and complications. ${ }^{16}$

The Swedish Patient Registry: The Patient Register comprises information on all in-hospital care and outpatient specialist care in Sweden, including codes for diagnoses and surgical procedures. It has a complete nationwide coverage of inpatient data since 1987, and complete outpatient specialist care data since 2001. The validity of oesophageal cancer surgery in the Patient Registry has recently been assessed. Among 1358 patients with a code representing oesophageal resection in the Patient Registry in 1987-2005, the positive predictive value was $99.6 \% .^{17}$ Data on comorbidity at the time of surgery were collected from this registry.

The National Education Registry: This registry was established by Statistics Sweden in 1985, and is annually updated with information on the highest formal education attained by each individual, from elementary to postgraduate level. ${ }^{18}$ Data on the study exposure and education level were collected from this registry.
Swedish Causes of Death Registry: This registry contains information on date of death for all deceased Swedish residents since 1952, and has a $99.2 \%$ completeness of cause-specific death. ${ }^{19}$ Data on mortality were collected from this registry.

\section{Study exposure}

The study exposure was the highest attained education level (partially or fully completed) at the time of surgery, and was classified into three categories based on the Swedish National School Administration and Statistics Sweden: (1) 'compulsory' education or $\leq 9$ years: primary and lower secondary education (up to the age of 16 years), (2) 'moderate' education or 10-12 years: upper secondary education (standard is 3 years) and (3) 'high' education or $\geq 13$ years: postsecondary education.

\section{Study outcomes}

The outcomes were (1) overall mortality up to 5 years after oesophagectomy for oesophageal or cardia cancer, the main outcome measure, (2) conditional mortality, defined as mortality within 5 years of surgery after exclusion of the first 90 days (short-term mortality) after surgery, (3) disease-specific mortality, representing all deaths with oesophageal or cardia cancer as an underlying or contributing cause of death within 5 years of surgery, (4) conditional and disease-specific 5-year mortality and (5) short-term mortality (within 90 days of surgery), which was analysed for completeness.

\section{Statistical analyses}

Cox regression was used to assess the association between the level of education and mortality, expressed as HRs with 95\% CIs. The patient group in the highest category of education was used as the reference group. Three regression models were used (1) a crude model without any adjustments, (2) a second model adjusted for sex, age $(<60,60-74$ or $\geq 75$ years $)$ and tumour stage (0-I, II, III or IV) and (3) a fully adjusted model further adjusted for histological type (adenocarcinoma or squamous cell carcinoma), the number of major complications $(0,1$ or $>1)$, the number of comorbidities $(0,1$ or $>1$ ) and surgeon volume ( $<8$ or $\geq 8$ oesophagectomies/ year). Tumour stage was categorised according to the TNM classification presented by the 'Union Internationale Contre le Cancer'. ${ }^{20}$ Predefined major medical and surgical complications which occurred within 30 days of surgery were extracted from the SECC database and included the following: anastomotic leakage, serious infections, respiratory insufficiency, cardiac failure, renal or liver failure, technical complications, damage to the recurrent laryngeal nerve or the thoracic duct, early anastomotic stricture and others (embolus, deep venous thrombosis, rupture of the wound, intestinal obstruction, myocardial infarction or stroke, all with a need for intervention). Data on comorbidity present at the time of surgery were extracted from the patient register, and included the 
following: diabetes mellitus, cardiovascular disease, pulmonary disease, hepatic or renal disease, renal failure and other cancer. Comorbidities within the same group (eg, two different cardiovascular diseases) were counted only once. Surgeon volume was categorised into two equally sized groups based on the median number of operations per surgeon and year. ${ }^{21} 22$ To assess effect modification, stratified survival analyses were performed for tumour stage and histological type. The same three regression models were used in the stratified analyses, but without adjustment for the stratifying variable. To test for interaction, a fully adjusted model was used with the patient group in the highest category of education with tumour stage I as the reference group.

\section{RESULTS}

\section{Patients}

From the study cohort, 616 patients were originally identified, which corresponded to $90 \%$ of all eligible patients in Sweden who underwent oesophageal or cardia cancer surgery during the inclusion period. Of these, 16 patients were excluded from the analyses because of missing values for education $(\mathrm{N}=6)$, tumour stage $(\mathrm{N}=9)$ or histology $(\mathrm{N}=1)$, leaving 600 patients for final analysis. Some characteristics of the study patients are described in table 1 . Of all patients, $281(46.8 \%)$ had compulsory education, $238(39.7 \%)$ had moderate education and 81 $(13.5 \%)$ had high education. Compared with the compulsory educated group, patients in the higher educated groups were younger, but the sex distribution was similar in all groups (approximately 80\% male). Distribution of tumour stage was comparable among the three education groups, while the proportion of squamous cell carcinoma was slightly higher in the compulsory educated group compared with the highly educated group (26\% vs 22\%). The highly educated group had a lower frequency of comorbidity compared with the compulsory educated group (53\% vs 64\%). The proportions of patients operated on by surgeons with high or low

Table 1 Demographic, treatment and tumour characteristics and mortality after oesophagectomy for cancer, categorised by the education level

\begin{tabular}{|c|c|c|c|c|}
\hline & \multicolumn{3}{|c|}{ Level of education* } & \multirow[b]{2}{*}{$\begin{array}{l}\text { Total } \\
\text { N (\%) }\end{array}$} \\
\hline & $\begin{array}{l}\geq 13 \text { years } \\
\mathrm{N}(\%)\end{array}$ & $\begin{array}{l}10-12 \text { years } \\
\mathrm{N}(\%)\end{array}$ & $\begin{array}{l}\leq 9 \text { years } \\
\mathrm{N}(\%)\end{array}$ & \\
\hline Total & $81(13.5)$ & $238(39.7)$ & $281(46.8)$ & $600(100.0)$ \\
\hline \multicolumn{5}{|l|}{ Age (years) } \\
\hline$<60$ & 27 (33.3) & $74(31.1)$ & $43(15.3)$ & $144(24.0)$ \\
\hline $60-74$ & 48 (59.3) & $126(52.9)$ & $161(57.3)$ & 335 (55.8) \\
\hline$\geq 75$ & $6(7.4)$ & $38(16.0)$ & 77 (27.4) & $121(20.2)$ \\
\hline \multicolumn{5}{|l|}{ Sex } \\
\hline Male & $64(79.0)$ & $188(79.0)$ & $230(81.9)$ & $482(80.3)$ \\
\hline Female & $17(21.0)$ & $50(21.0)$ & $51(18.2)$ & $118(19.7)$ \\
\hline \multicolumn{5}{|l|}{ Tumour stage } \\
\hline 1 & $19(23.5)$ & 45 (18.9) & 49 (17.4) & $113(18.8)$ \\
\hline II & $19(23.5)$ & $73(30.7)$ & $84(29.9)$ & $176(29.3)$ \\
\hline III & $34(42.0)$ & $91(38.2)$ & $117(41.6)$ & $242(40.3)$ \\
\hline IV & $9(11.1)$ & 29 (12.2) & $31(11.0)$ & 69 (11.5) \\
\hline \multicolumn{5}{|l|}{ Histology } \\
\hline Adenocarcinoma & $63(77.8)$ & 183 (76.9) & $208(74.0)$ & $454(75.7)$ \\
\hline Squamous cell carcinoma & $18(22.2)$ & $55(23.1)$ & $73(26.0)$ & $146(24.3)$ \\
\hline \multicolumn{5}{|l|}{ Comorbidity } \\
\hline None & 38 (46.9) & 95 (39.9) & $101(35.9)$ & $234(39.0)$ \\
\hline One & $28(34.6)$ & $92(38.7)$ & 88 (31.3) & 208 (34.7) \\
\hline More than one & 15 (18.5) & $51(21.4)$ & $92(32.7)$ & $158(26.3)$ \\
\hline \multicolumn{5}{|l|}{ Surgical volume } \\
\hline Low (<8 operations/year) & $42(51.9)$ & $119(50.0)$ & $153(54.5)$ & $314(52.3)$ \\
\hline High ( $\geq 8$ operations/year) & $39(48.2)$ & $119(50.0)$ & $128(45.5)$ & $286(47.7)$ \\
\hline \multicolumn{5}{|l|}{ Postoperative complications } \\
\hline None & $46(56.8)$ & $158(66.4)$ & $175(62.3)$ & $379(63.2)$ \\
\hline One & $20(24.7)$ & 53 (22.3) & 68 (24.2) & $141(23.5)$ \\
\hline More than one & $15(18.5)$ & $27(11.3)$ & $38(13.5)$ & $80(13.3)$ \\
\hline \multicolumn{5}{|l|}{ Mortality } \\
\hline Within 90 days & $5(6.2)$ & $19(8.0)$ & $24(8.5)$ & $48(8.0)$ \\
\hline Overall within 5 years & 55 (67.9) & $180(75.6)$ & $216(76.9)$ & $451(75.2)$ \\
\hline Conditional within 5 years $\dagger$ & $50(65.8)$ & $161(73.5)$ & $192(74.7)$ & $403(73.0)$ \\
\hline
\end{tabular}


annual volume were similar between the education groups. No major differences in the number of postoperative complications were found between the educational levels. In total, 451 (75.2\%) patients died within 5 years of surgery, of whom $425(94.2 \%)$ had oesophageal or cardia cancer as an underlying or contributing cause of death.

\section{Education level and mortality}

All tumour stages

The frequencies of overall 5-year mortality, conditional 5-year mortality and short-term mortality were highest in the compulsory educated group, closely followed by the moderately educated group and lowest in patients with high education (table 1 ). The overall 5-year survival rates were $23.1 \%, 24.4 \%$ and $32.1 \%$ among patients with compulsory, moderate and high education, respectively. Table 2 presents the HRs for mortality after oesophagectomy according to the education level of all included patients. The crude model showed increased overall point HRs in the compulsory (HR 1.30, 95\% CI 0.97 to 1.74 ) and moderately educated groups (HR $1.16,95 \%$ CI 0.85 to 1.56 ) compared with the reference group (high education), but without statistical significance. The point HRs became slightly attenuated after adjustment in the second model (HR 1.11, 95\% CI 0.81 to 1.51 ) and the third, fully adjusted model (HR $1.08,95 \%$ CI 0.80 to 1.47). The HRs for mortality within 5 years of surgery were similar when only disease-specific deaths were considered, as well as when the first 90 days were excluded from the analyses (table 2). Regarding short-term (90 days) mortality, no difference was identified between the compulsory educated and the highly educated in the fully adjusted model (HR 0.98, 95\% CI 0.36 to 2.67 ).

\section{Specific tumour stages}

The tumour stage-specific analyses addressing the overall 5 -year mortality indicated some differences in survival between the education groups (table 3). In tumour stage I, the fully adjusted point HRs for compulsory and moderately educated patients were increased compared with patients in the highest level of education, but no statistically significant differences were found (HR 2.39, $95 \%$ CI 0.81 to 7.07 and HR $1.53,95 \%$ CI 0.49 to 4.78 , respectively). In tumour stage IV, the fully adjusted HRs were almost threefold increased in compulsory and moderately educated patients compared with highly educated patients (HR 2.88, 95\% CI 1.07 to 7.73 and HR 2.83, $95 \%$ CI 1.15 to 6.95 ). When the patient group with tumour stage I and the highest level of education was used as the reference group, survival was significantly worse in all groups with tumour stages II-IV (table 4).

\section{Specific histological types}

The crude 5-year overall survival analyses stratified for histological type indicated the associations between

Table 2 Multivariable Cox regression models analysing the association between education level and mortality after oesophagectomy for cancer, expressed as $\mathrm{HR}$ with $95 \% \mathrm{Cl}$

\begin{tabular}{|c|c|c|c|}
\hline & \multicolumn{3}{|l|}{ Level of education* } \\
\hline & $\geq 13$ years (Reference) & 10-12 years HR $(95 \% \mathrm{Cl})$ & $\leq 9$ years $\mathrm{HR}(95 \% \mathrm{Cl})$ \\
\hline \multicolumn{4}{|c|}{ Overall 5-year mortality } \\
\hline Model 1 & 1 & $1.16(0.85$ to 1.56$)$ & $1.30(0.97$ to 1.74$)$ \\
\hline Model 2 & 1 & $1.04(0.77$ to 1.41$)$ & $1.08(0.80$ to 1.46$)$ \\
\hline Model 3 & 1 & $1.08(0.80$ to 1.47$)$ & $1.11(0.81$ to 1.51$)$ \\
\hline \multicolumn{4}{|c|}{ Conditional overall 5-year mortality $†$} \\
\hline Model 1 & 1 & $1.14(0.83$ to 1.57$)$ & $1.29(0.95$ to 1.76$)$ \\
\hline Model 2 & 1 & $1.03(0.75$ to 1.42$)$ & $1.09(0.79$ to 1.50$)$ \\
\hline Model 3 & 1 & 1.07 (0.78 to 1.48$)$ & $1.13(0.82$ to 1.57$)$ \\
\hline \multicolumn{4}{|c|}{ Disease-specific 5-year mortality $\ddagger$} \\
\hline Model 1 & 1 & $1.15(0.85$ to 1.57$)$ & 1.32 (0.98 to 1.79$)$ \\
\hline Model 2 & 1 & 1.04 (0.76 to 1.42$)$ & $1.12(0.82$ to 1.53$)$ \\
\hline Model 3 & 1 & $1.09(0.80$ t 01.48$)$ & $1.16(0.85$ to 1.59$)$ \\
\hline \multicolumn{4}{|c|}{ Conditional† and disease-specific $\ddagger$ 5-year mortality } \\
\hline Model 1 & 1 & $1.16(0.84$ to 1.61$)$ & $1.32(0.96$ to 1.82$)$ \\
\hline Model 2 & 1 & $1.06(0.76$ to 1.46$)$ & $1.13(0.81$ to 1.56$)$ \\
\hline Model 3 & 1 & 1.09 (0.79 to 1.52$)$ & $1.19(0.85$ to 1.65$)$ \\
\hline \multicolumn{4}{|c|}{ Overall 90-day mortality } \\
\hline Model 1 & 1 & $1.28(0.48$ to 3.42$)$ & 1.37 (0.52 to 3.59$)$ \\
\hline Model 2 & 1 & 1.08 (0.40 to 2.92$)$ & $1.00(0.37$ to 2.70$)$ \\
\hline Model 3 & 1 & 1.25 (0.46 to 3.42$)$ & 0.98 (0.36 to 2.67$)$ \\
\hline
\end{tabular}

Values are expressed as HRs.

*Level of education: $\geq 13$ years: postsecondary education; $10-12$ years: upper secondary education; $\leq 9$ years: compulsory education. †Conditional mortality: excluding first 90 days after surgery.

‡Disease-specific mortality: oesophageal or cardia cancer as underlying or contributing cause. Model 1: unadjusted. Model 2: adjusted for sex, age and tumour stage. Model 3: adjusted for sex, age, tumour stage, histology, major complications, comorbidity and surgeon volume. 
Table 3 Multivariable Cox regression models analysing the association between education level and all-cause 5-year mortality after oesophagectomy for cancer, stratified by tumour stage and expressed as HRs with $95 \% \mathrm{Cls}$

\begin{tabular}{|c|c|c|c|c|}
\hline & \multicolumn{3}{|l|}{ Level of education* } & \multirow[b]{2}{*}{ Total number (\%) } \\
\hline & $\geq 13$ years (Reference) & $10-12$ years HR $(95 \% \mathrm{Cl})$ & $\leq 9$ years $\mathrm{HR}(95 \% \mathrm{Cl})$ & \\
\hline \multicolumn{5}{|l|}{ Model 1} \\
\hline Stage I & 1 & 1.55 (0.51 to 4.70$)$ & $2.71(0.94$ to 7.84$)$ & $113(18.8)$ \\
\hline Stage II & 1 & $1.31(0.72$ to 2.39$)$ & $1.18(0.65$ to 2.14$)$ & $176(29.3)$ \\
\hline Stage III & 1 & 0.85 (0.56 to 1.30$)$ & $1.03(0.69$ to 1.55$)$ & $242(40.3)$ \\
\hline Stage IV & 1 & 1.47 (0.67 to 3.24$)$ & 1.33 (0.61 to 2.92$)$ & 69 (11.5) \\
\hline \multicolumn{5}{|l|}{ Model 2} \\
\hline Stage I & 1 & $1.64(0.53$ to 5.06$)$ & $2.56(0.88$ to 7.51$)$ & $113(18.8)$ \\
\hline Stage II & 1 & $1.12(0.61$ to 2.06$)$ & 0.89 (0.48 to 1.64$)$ & $176(29.3)$ \\
\hline Stage III & 1 & 0.81 (0.53 to 1.24$)$ & 0.98 (0.65 to 1.49$)$ & $242(40.3)$ \\
\hline Stage IV & 1 & $1.52(0.69$ to 3.38$)$ & 1.30 (0.58 to 2.90$)$ & 69 (11.5) \\
\hline \multicolumn{5}{|l|}{ Model 3} \\
\hline Stage I & 1 & 1.53 (0.49 to 4.78$)$ & 2.39 (0.81 to 7.07$)$ & $113(18.8)$ \\
\hline Stage II & 1 & 0.96 (0.51 to 1.79$)$ & 0.81 (0.43 to 1.54$)$ & 176 (29.3) \\
\hline Stage III & 1 & 0.89 (0.58 to 1.37$)$ & $1.03(0.67$ to 1.57$)$ & $242(40.3)$ \\
\hline Stage IV & 1 & 2.83 (1.15 to 6.95$)$ & 2.88 (1.07 to 7.73$)$ & 69 (11.5) \\
\hline
\end{tabular}

Values are expressed as HRs or as number of patients (\%).

Model 1: unadjusted; model 2: adjusted for sex and age; model 3: adjusted for sex, age, histology, major complications, comorbidity and surgeon volume.

*Level of education: $\geq 13$ years: postsecondary education; $10-12$ years: upper secondary education; $\leq 9$ years: compulsory education.

compulsory education and survival in patients with adenocarcinoma, but the HRs were attenuated after full adjustments (HR 1.13, 95\% CI 0.79 to 1.62 and HR 1.11, $95 \%$ CI 0.77 to 1.58 ; table 5 ). The adjusted point HRs for squamous cell carcinoma were also increased among compulsory and moderately educated groups compared with the highly educated group, but no statistically significant differences were identified (HR 1.18, 95\% CI 0.61 to 2.30 and $\mathrm{HR} 1.26,95 \%$ CI 0.65 to 2.44, respectively).

\section{DISCUSSION}

This study does not provide much evidence for the hypothesis that the education level influences the longterm survival after surgery for oesophageal cancer, with the exception of worse survival in compulsory educated groups with advanced tumours (stage IV).
The strengths of this study include the nationwide population-based design with a high participation rate and completeness of the follow-up, consequently reducing the risk for selection bias. The results have also been adjusted for confounding by known prognostic factors. Moreover, the exposure and outcome measures were robust, especially because we limited our study to one exposure as proxy for socioeconomic status. We also considered using income or occupation-based measures of socioeconomic position but chose individual educational level as it is robust and easy to measure. Income is rather complex to measure as one has to take the wealth and the numbers supported by the income into account. The last updated Census in Sweden on an occupation-based measure was in $1990 .{ }^{23}{ }^{24}$ Therefore, we limited this study to the education status only.

A weakness is the limited statistical power to detect weak or moderate differences, particularly in the

Table 4 Multivariable Cox regression models analysing the association between education level and all-cause 5-year mortality after oesophagectomy for cancer, stratified by tumour stage, and expressed as HRs with $95 \% \mathrm{Cls}$, with tumour stage I in the high educated group as reference

\begin{tabular}{|c|c|c|c|c|}
\hline & \multicolumn{3}{|l|}{ Level of education* } & \multirow[b]{2}{*}{ Total number (\%) } \\
\hline & $\geq 13$ years & $\begin{array}{l}10-12 \text { years } \\
\text { HR }(95 \% \mathrm{Cl})\end{array}$ & $\begin{array}{l}\leq 9 \text { years } \\
\mathrm{HR}(95 \% \mathrm{Cl})\end{array}$ & \\
\hline \multicolumn{5}{|l|}{ Model 3} \\
\hline Stage I & 1 & $1.56(0.51$ to 4.76$)$ & $2.43(0.84$ to 7.05$)$ & $113(18.8)$ \\
\hline Stage II & 5.47 (1.77 to 16.87$)$ & $6.13(2.22$ to 16.92$)$ & $5.54(2.00$ to 15.39$)$ & $176(29.3)$ \\
\hline Stage III & 10.31 (3.62 to 29.39 ) & 9.01 (3.28 to 24.74 ) & 9.87 (3.61 to 26.94$)$ & $242(40.3)$ \\
\hline Stage IV & 12.65 (3.78 to 42.38$)$ & 19.03 (6.63 to 54.62$)$ & 15.49 (5.41 to 44.33$)$ & 69 (11.5) \\
\hline
\end{tabular}

Values are expressed as HRs or as number of patients (\%).

Model 3: adjusted for sex, age, histology, major complications, comorbidity and surgeon volume.

*Level of education: $\geq 13$ years: postsecondary education; $10-12$ years: upper secondary education; $\leq 9$ years: compulsory education. 
Table 5 Multivariable Cox regression models analysing the association between education level and all-cause 5-year mortality after oesophagectomy for cancer, stratified by tumour histology and expressed as $\mathrm{HRs}$ with $95 \% \mathrm{Cl}$

\begin{tabular}{|c|c|c|c|c|}
\hline & \multicolumn{3}{|c|}{ Level of education* } & \multirow[b]{2}{*}{ Total number (\%) } \\
\hline & $\begin{array}{l}13 \text { years } \\
\text { (Reference) }\end{array}$ & $\begin{array}{l}\text { 10-12 years } \\
\text { HR }(95 \% \mathrm{Cl})\end{array}$ & $\begin{array}{l}\leq 9 \text { years } \\
\text { HR }(95 \% \mathrm{Cl})\end{array}$ & \\
\hline $\begin{array}{l}\text { Overall 5-year mortality } \\
\text { Model } 1\end{array}$ & $55 / 81(67.9)$ & $180 / 238(75.6)$ & $216 / 281$ (76.9) & $451 / 600(75.2)$ \\
\hline Adenocarcinoma & 1 & $1.20(0.85$ to 1.70$)$ & 1.41 (1.00 to 1.98$)$ & $454(75.7)$ \\
\hline Squamous cell carcinoma & 1 & $1.00(0.55$ to 1.83$)$ & 0.99 (0.55 to 1.78$)$ & $146(24.3)$ \\
\hline \multicolumn{5}{|l|}{ Model 2} \\
\hline Adenocarcinoma & 1 & $1.03(0.72$ to 1.46$)$ & 1.07 (0.75 to 1.52$)$ & $454(75.7)$ \\
\hline Squamous cell carcinoma & 1 & 1.06 (0.57 to 1.97$)$ & 1.01 (0.55 to 1.87$)$ & $146(24.3)$ \\
\hline \multicolumn{5}{|l|}{ Model 3} \\
\hline Adenocarcinoma & 1 & $1.11(0.77$ to 1.58$)$ & 1.13 (0.79 to 1.62$)$ & $454(75.7)$ \\
\hline Squamous cell carcinoma & 1 & 1.26 (0.65 to 2.44$)$ & $1.18(0.61$ to 2.30$)$ & $146(24.3)$ \\
\hline
\end{tabular}

stratified analyses. Despite the inclusion of the vast majority of all patients operated in Sweden during the nearly 5-year inclusion period, who it was possible to follow-up for at least 5 years, the low incidence of oesophageal cancer in Sweden combined with a low resection rate $(25 \%)$ reduced the sample size. A post hoc power analysis showed that if the HR would have been 1.43 or higher, the power for this study cohort would have been at least $80 \%$. An adjusted HR of 1.19 (table 3) would, for example, require a sample size of 2500 patients in the study cohort assuming similar conditions as those of the present study. Therefore, even larger studies are needed to statistically verify the level of potential associations indicated in the present study.

Since the inclusion period was limited, differences in the therapeutic management are unlikely to have influenced the survival. The multicentre design, where several hospitals and surgeons were involved in the treatment of these patients, might have influenced the survival, but it is unlikely that the referral patterns would be different between the education groups. Finally, confounding by other factors than those adjusted for could influence the results.

An interesting question is why the differences in education in oesophageal cancer seem to be a less strong prognostic factor compared with other cancer types. ${ }^{6-10} \mathrm{~A}$ British study compared the 'deprivation gap', or the percentage difference in a 5-year survival between the most affluent and most deprived patients in 17 different cancer types, and showed major differences for cancer of the larynx $(17 \%)$, colon $(6-7 \%)$, rectum $(8-9 \%)$, prostate $(7 \%)$, bladder $(6 \%)$ and breast $(6 \%)$, but not for the oesophagus (in men $1.9 \%$, in women $0.2 \%$ ), stomach $(1.7 \%)$, pancreas $(1 \%)$ or ovary $(1 \%) .{ }^{25}$ These results, supported by the findings of the present study, may suggest that the possible impact of the socioeconomic position might be restricted by the high overall mortality rates in oesophageal cancer.

Any baseline difference between the educational groups is deemed of limited impact, since the great majority of deaths within the 5 years after operation for oesophageal cancer $(95 \%)$ are because of cancer recurrence. ${ }^{26}{ }^{27}$ We censored our data at 5 years after surgery, because deaths after this period are less likely to be related to cancer recurrence. Therefore the mortality rate should be similar as for the background population.

The reasons for the differences in survival between compulsory and highly educated patients with advanced tumour (stage IV) are unclear, and we can only speculate. Highly educated patients with advanced disease might receive (and possibly also request) a more aggressive preoperative and postoperative treatment, which might result in a longer average survival period that would influence the HR for overall mortality. These findings are supported by a recent study, which showed an increased survival for patients with higher income levels, and a correlation between higher income and receiving curative treatment (including surgery and radiotherapy). ${ }^{28}$ Even a small increase in the length of survival in our group of patients with high education could be responsible for these significant results. Yet, although the prognosis is poor for patients with tumour stage 4, these differences are not purely due to the differences in the short-term survival, since $5.8 \%$ of these patients survive at least 5 years after surgery.

The clinical implications of this study are limited, since the overall results suggest that the impact of education on survival after oesophagectomy could be low or even absent. Yet, it could be discussed that more effort should be placed on the lower educated patients, as they could have more risk factors for mortality such as increased comorbidity, as shown in the present study. Nevertheless, continuous efforts are needed to guarantee an optimal 
treatment for all patients, including patients with suspected low compliance to treatment, follow-up and lifestyle recommendations.

To conclude, this population-based, nationwide and prospective cohort study provides a limited evidence of education being a prognostic factor after oesophagectomy for cancer. However, the increased mortality in lower educated groups with tumour stage IV warrants further attention. In addition, the generally increased point risk estimates combined with a limited statistical power indicate a need for studies with very large sample sizes that can allow for detailed stratification of the analyses.

Contributors All authors contributed equally to the study design and study protocol. PL and JL were responsible for the data collection. FM and NB performed the statistical analyses and interpreted the results. The writing and revisions of the manuscript have been performed by NB. Critical evaluation of the manuscript was performed equally by all authors.

Funding This work was supported by the Swedish Research Council (SIMSAM) (grant number 2008-7496) and Swedish Cancer Society (grant number 120748).

Competing interests None.

Patient consent Obtained.

Ethics approval The study was approved by the Regional Ethical Review Board in Stockholm, Sweden.

Provenance and peer review Not commissioned; externally peer reviewed.

Data sharing statement : No additional data are available.

Open Access This is an Open Access article distributed in accordance with the Creative Commons Attribution Non Commercial (CC BY-NC 3.0) license, which permits others to distribute, remix, adapt, build upon this work noncommercially, and license their derivative works on different terms, provided the original work is properly cited and the use is non-commercial. See: http:// creativecommons.org/licenses/by-nc/3.0/

\section{REFERENCES}

1. Lagergren J, Lagergren P. Oesophageal cancer. BMJ 2010;341:c6280.

2. Sant M, Allemani $C$, Santaquilani M, et al. EUROCARE Working Group. EUROCARE-4. Survival of cancer patients diagnosed in 1995-1999. Results and commentary. Eur J Cancer 2009;45:931-91.

3. Gossage JA, Forshaw MJ, Khan AA, et al. The effect of economic deprivation on oesophageal and gastric cancer in a UK cancer network. Int J Clin Pract 2009;63:859-64.

4. Jansson $\mathrm{C}$, Johansson $\mathrm{AL}$, Nyren $\mathrm{O}$, et al. Socioeconomic factors and risk of esophageal adenocarcinoma: a nationwide Swedish case-control study. Cancer Epidemiol Biomarkers Prev 2005;14:1754-61.

5. Jemal A, Simard EP, Xu J, et al. Selected cancers with increasing mortality rates by educational attainment in 26 states in the United States, 1993-2007. Cancer Causes Control 2013;24:559-65.

6. Cavalli-Bjorkman N, Lambe M, Eaker S, et al. Differences according to educational level in the management and survival of colorectal cancer in Sweden. Eur J Cancer 2011;47:1398-406.

7. Eloranta S, Lambert PC, Cavalli-Bjorkman N, et al. Does socioeconomic status influence the prospect of cure from colon cancer-a population-based study in Sweden 1965-2000. Eur J Cancer 2010;46:2965-72.

8. Sorbye $\mathrm{H}$, Pfeiffer P, Cavalli-Bjorkman N, et al. Clinical trial enrollment, patient characteristics, and survival differences in prospectively registered metastatic colorectal cancer patients. Cancer 2009;115:4679-87.

9. Bentley R, Kavanagh AM, Subramanian SV, et al. Area disadvantage, individual socio-economic position, and premature cancer mortality in Australia 1998 to 2000: a multilevel analysis. Cancer Causes Control 2008;19:183-93.

10. Frederiksen $\mathrm{BL}$, Osler $\mathrm{M}$, Harling $\mathrm{H}$, et al. Do patient characteristics, disease, or treatment explain social inequality in survival from colorectal cancer? Soc Sci Med 2009;69:1107-15.

11. Thrift AP, Nagle CM, Fahey PP, et al. Predictors of survival among patients diagnosed with adenocarcinoma of the esophagus and gastroesophageal junction. Cancer Causes Control 2012;23: 555-64.

12. Morgan MA, Lewis WG, Chan DS, et al. Influence of socio-economic deprivation on outcomes for patients diagnosed with oesophageal cancer. Scand J Gastroenterol 2007;42:1230-7.

13. Rouvelas I, Zeng W, Lindblad M, et al. Survival after surgery for oesophageal cancer: a population-based study. Lancet Oncol 2005;6:864-70.

14. Leigh $\mathrm{Y}$, Seagroatt $\mathrm{V}$, Goldacre $\mathrm{M}$, et al. Impact of socio-economic deprivation on death rates after surgery for upper gastrointestinal tract cancer. Br J Cancer 2006;95:940-3.

15. Lagergren J, Bergström R, Lindgren A, et al. Symptomatic gastroesophageal reflux as a risk factor for esophageal adenocarcinoma. N Engl J Med 1999;340:825-31.

16. Viklund $\mathrm{P}$, Lindblad M, Lu M, et al. Risk factors for complications after esophageal cancer resection: a prospective population-based study in Sweden. Ann Surg 2006;243:204-11.

17. Lagergren K, Derogar M. Validation of oesophageal cancer surgery data in the Swedish Patient Registry. Acta Oncol 2012;51:65-8.

18. Statistics Sweden. Yearbook of educational statistics: statistics Sweden (Utbildningsstatistisk -årsbok 2013). Sweden: Statistiska Centralbyrån, 2013:8-9.

19. Johansson LA, Westerling R. Comparing Swedish hospital discharge records with death certificates: implications for mortality statistics. Int J Epidemiol 2000;29:495-502.

20. Sobin L, Wittekind C. International union against cancer (UICC): classification of malignant tumours. 6th edn, 2002.

21. Coupland VH, Lagergren J, Luchtenborg M, et al. Hospital volume, proportion resected and mortality from oesophageal and gastric cancer: a population-based study in England, 2004-2008. Gut 2012;62:961-6.

22. Derogar M, Sadr-Azodi O, Johar A, et al. Hospital and surgeon volume in relation to survival after esophageal cancer surgery in a population-based study. J Clin Oncology 2013;31:551-7.

23. Geyer S, Hemstrom O, Peter R, et al. Education, income, and occupational class cannot be used interchangeably in social epidemiology. Empirical evidence against a common practice. $J$ Epidemiol Community Health 2006;60:804-10.

24. Kunst AE, Groenhof F, Borgan JK, et al. Socio-economic inequalities in mortality. Methodological problems illustrated with three examples from Europe. Rev Epidemiol Sante Publique 1998;46:467-79.

25. Coleman MP, Rachet B, Woods LM, et al. Trends and socioeconomic inequalities in cancer survival in England and Wales up to 2001. Br J Cancer 2004:90:1367-73.

26. Sundelof M, Ye W, Dickman PW, et al. Improved survival in both histologic types of oesophageal cancer in Sweden. Int J Cancer 2002;99:751-4.

27. Derogar M, Sadr-Azodi O, Johar A, et al. Hospital and surgeon volume in relation to survival after esophageal cancer surgery in a population-based study. J Clin Oncol 2013;31:551-7.

28. Chen MF, Yang YH, Lai CH, et al. Outcome of patients with esophageal cancer: a nationwide analysis. Ann Surg Oncol 2013;20:3023-30. 